\title{
The Effect of Cross-curricular Instruction on Reading Comprehension
}

\author{
Yasin Aslan \\ Department of Foreign Languages, Faculty of Education, Sinop University, Turkey
}

Copyright $\bigcirc 2016$ by authors, all rights reserved. Authors agree that this article remains permanently open access under the terms of the Creative Commons Attribution License 4.0 international License.

\begin{abstract}
Cross-curricular objectives serve as a kind of 'safety net' for core objectives. Firstly, cross-curricular objectives refer to competencies that do not pertain to the content of one or more subjects, but that can be taught, practised and applied in it, such as learning to learn and social skills. Secondly, certain cross-curricular final objectives must also be regarded as a complement to the subject final objectives. They render it possible to make the subjects more coherent and interconnected. Several studies show that without enough background familiarity with L2 cultural knowledge, readers have great difficulty in understanding the meaning of texts. This study describes strategies of cross-curricular reading instruction, discusses its benefits, advantages and challenges for teachers or other interested groups who want to encourage their students to explore significant subjects, problems, and questions by providing them with a wide range of reading opportunities. It presents suggestions for teaching themes that focus on what students know, because such themes increase confidence, improve reading skills, expand concepts and background, and foster positive attitudes about reading.
\end{abstract}

Keywords Reading, Cross-curricular Teaching, Culture, Background Knowledge

\section{Introduction}

Reading is one of the most important skills for daily life. People usually read because they want to get information about various topics. Reading comprehension is a dynamic mental activity in which the reader interacts with the passage to extract meaning. Unlike previous beliefs that reading is a passive skill, it is now regarded as a process in which the reader picks out available information and cross-cultural familiarity only enough to understand the meaning of the text. In a text, words are combined in such a way that their relative position andpatterns contribute to their collective meaning (Farhady, [1]).
Teachers who use cross-curricular themes create active readers by engaging students in authentic literacy tasks that emerge naturally from interesting and worthwhile topics and ideas. Authentic tasks focus on student choice and ownership; extend beyond the classroom walls; involve a variety of reading and writing opportunities; promote discussion and collaboration; and build upon students' interests, abilities, background, and language development (Hiebert, [2]; Paris et al., [3]). Cross-curricular themes integrate a variety of content areas, such as science, social studies, art, and so forth. Good readers connect and utilize ideas and information from a variety of previous life and literacy experiences (Anderson et al, [4]). Sustained reading of interesting texts improves reading comprehension and enhances enjoyment (Fielding \& Pearson, [5]; Reutzel \& Cooter, [6]). Over time, the effect is that comprehension improves as students read more (Hartman \& Hartman, [7]). Thus, to increase understanding, students should gain experience in reading a variety of texts, including narrative and expository literature, as well as "real world" materials such as brochures, magazine articles, maps, and informational signs. Because our lives require us to integrate what we have learned in an interdisciplinary manner, teaching children through merged disciplines better prepares them for applying new knowledge and experience. In addition, when students view their learning as having personal relevance, they put more effort into their schoolwork and achievement (Willis, [8]).

Using students' backgrounds, knowledge and experiences to inform learning in the classroom and during reading instruction is of great significance. Schools and teachers should try to build a bridge between students' home and school lives. Ladson, [9]) defines culturally-compatible teaching as a kind of teaching that is designed not only to fit the school culture to the students' culture but also to use student culture as the basis for helping students understand themselves and others, structure social interactions, and conceptualize knowledge.

It is necessary for teachers and schools to not only provide all students with the tools to achieve academic 
proficiency, but to also make each and every student feel comfortable regardless of their ethnic, racial and inguistic background. Also, culturally talented teachers are adept at using students' cultures as a vehicle for learning and provide students with a curriculum based on their prior knowledge. A key aspect of this requires actively encouraging students to maintain their cultural integrity in the classroom. For instance, students who speak second languages, or who do not have 'standard' English for their primary discourse, should not be discouraged from using their primary or home language in the classroom.

Culturally relevant instruction help students develop a broader sociopolitical consciousness through engaging in the world and with others critically. Students are encouraged to interrogate "the cultural norms, values, mores, and institutions that produce and maintain social iniquities." This concept is closely related to that of "critical literacy" whereby learners adopt critical perspectives toward texts such as songs, poems, novels, conversations, pictures and movies. In culturally relevant reading instruction, texts are used to stimulate dialogue as regards prominent social subjects and institutions significant to students' lives, like family, government, equality, social justice, racism, poverty etc.

Teachers should be aware of the fact that students' knowledge and cultures are shaped by their sociocultural and sociolinguistic backgrounds, as well as the socioeconomic and political circumstances in which their lives take shape. Gender, ethnicity, race, language, religion, social class and generational group must all be taken into account in the classroom and during reading instruction. In addition, teachers must be able to function effectively within multiple cultural contexts. 'Cultural training' workshops or programs for teachers may be esseantial; however, it is admissible to assume that cultural competence can best be learned reciprocally alongside students in the context of respectful and culturally-sensitive daily interactions in the classroom.

\section{Advantages of Thematic Teaching}

Students and teachers alike enjoy reading and learning about topics and ideas that are interesting and challenging. Along with enjoyment, cross-curricular thematic instruction offers a number of other advantages (Cooper, [10]; Fredericks, Meinbach, \& Rothlein, [11]; Lapp \& Flood, [12]; Walmsley, [13]; Willis, [14]).

Thematic teaching enables students to:

- Integrate and enrich the language processes of reading, writing, listening, speaking, and thinking.

- Use prior knowledge of the world and past experiences with language and text.

- Acquire, communicate, and investigate worthwhile knowledge in depth.

- $\quad$ Practice reading different kinds of materials for varied purposes.

- Make choices, interact, collaborate, and cooperate.

- Apply what they learn in meaningful and "real world" contexts.

- Informally assess their understanding and application of what they are learning.

- Participate and learn, regardless of ability, level of language development, or background.

- Learn effectively in self-contained, multi-age, or departmental classrooms.

\section{The Purpose of the Study}

This study describes strategies of cross-curricular reading instruction, discusses its benefits, advantages and challenges for teachers or other interested groups who want to encourage their students to explore significant subjects, problems, and questions by providing them with a wide range of reading opportunities. After looking over the literature, this study tries to find an answer to the following question:

What is the effect of cross-cultural background knowledge instruction on reading comprehension?

\subsection{Planning and Choosing a Theme}

When planning, it is important to select themes that are not only interesting to students, but are meaningful and substantive. A theme on the environment helps students understand the importance of preserving and protecting the Earth. A theme on sports encourages students to engage in sports activities and stay healthy. Themes like these offer the opportunity to explore important ideas that challenge students to seek information beyond what they already know (Walmsley, [15]). For instance, students may understand the necessity of recycling bottles and cups in their own communities, but they may not know anything about the destruction of the Amazon rain forests. Relating and connecting these two ecological concerns through appropriate reading and writing tasks enables students to move beyond their own lives into the larger world.

After determining themes, the goal is to select tasks that encourage students to investigate, speculate, and problem-solve, asking questions that enable them to explore other topics more fully. Key concepts for a theme should provide a clear focus for all instruction and learning. For example, the key concept for a theme on the environment may be: "We should respect and preserve the natural world because our lives are linked to it." It is expected, by the end of the theme, which all students will begin to internalize, build upon, and transfer this key concept to their own lives.

\subsection{Identifying Strategies and Resources}


Reading materials may come from a variety of resources, including literature anthologies, trade books, and "real life" resources, such as magazines, brochures, and maps. Narrative and expository core literature anchor the theme, both for student reading and teacher read-aloud. Students may be involved in sharing other reading materials, such as thematically related books from their personal libraries, articles, family memoirs, computer software, newspapers, videos, or other relevant resources. In all, the reading materials for the theme are varied in terms of interest, genre, origin, and level of difficulty.

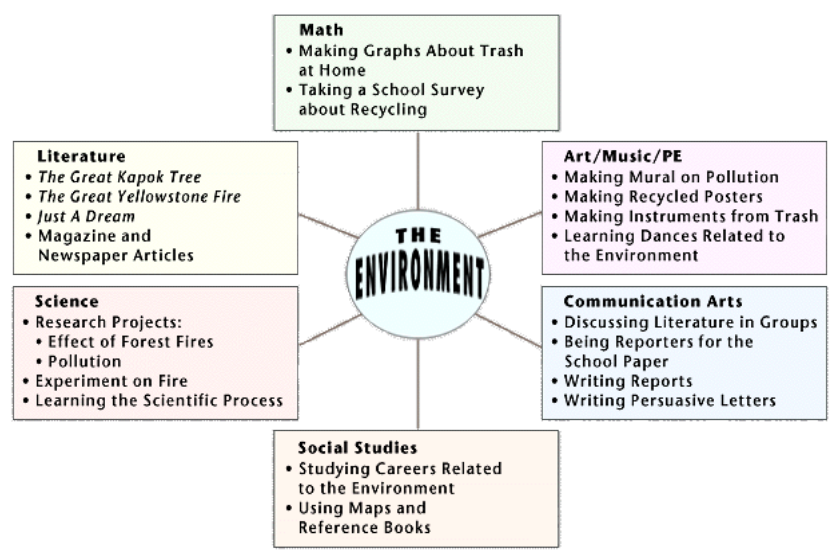

Figure 1. Sample Planning Web

In cross-curricular instruction, skills and strategies become an instrument for developing reading skills, rather than the end result of the thematic study. Specific skills, such as comparing and contrasting, can be taught through structured and carefully planned lessons or more interactive lessons for those students requiring in-depth teaching.

\section{Improving a Schedule}

Planning a schedule and time line for instruction is important as well. Some teachers prefer "theme immersion," in which the entire day, week, or month and all subjects of the curriculum revolve around the theme (Manning, Manning, \& Long, [16]). Others choose to plan themes for several weeks around core subjects, such as language arts and social science (Fredericks et al., [17]). Still others choose to integrate primarily the language arts, and incorporate several subject areas, if appropriate, for a small portion of the day (Vogt, [18]).

Whatever the choice, it is important to keep in mind students' interests and attention spans, the availability of resources and reading materials, and curriculum guidelines. When teaching a theme for the first time, it helps to monitor student interest and involvement and to be ready to modify the time line, if necessary. If it appears that students are ready to change to a new theme before all planned activities are completed, it is better to move on and begin something new. Because thematic teaching is flexible and adaptable, changes can be made in the schedule with little or no disruption.
While planning the schedule, the teacher's role should also be considered. At times the role is to facilitate, at others to provide explicit instruction, and sometimes simply to serve as a resource. Activities may be directed by the teacher or, occasionally, by the students themselves. Whether an activity is more effective with whole-class, small-group, or individual instruction depends on the difficulty of the reading selection, the nature of the activity and the abilities and interests of the students.

As mentioned, one of the advantages of thematic instruction is that it adapts to a variety of grouping configurations. Students may work together in heterogeneous cooperative learning groups, having the opportunity to take leadership roles, develop understanding, and improve social skills (Slavin, [19]). At other times, however, students may read and study with partners or "learning buddies". Grouping decisions may be made jointly by the teacher and students based upon which configuration might be the best for any particular activity.

Opportunities are also provided for students to work individually. Students are given time each day for self-selected reading. Moreover, whole-class instruction for some activities is efficient and appropriate. The type and difficulty of reading material, the nature and scope of the daily activities, the learning goals, and students' strengths and needs all affect scheduling.

When introducing a new theme, the teacher generates excitement and enthusiasm while assessing, activating, and building background knowledge about the theme's key concept. Opening activities should stimulate thinking and speculation. Students participate in brainstorming ideas they wish to explore or notions they find intriguing. They also may determine their own learning goals, along with ideas for accomplishing them. Learning teams are formed around areas of interest, partners are selected, and the theme's learning goals are shared. Students are encouraged to involve their families by bringing materials, pictures, books, and expertise from home.

Once the theme is launched, students begin to engage in reading and writing, in discussing and researching, in creating and generating. The teacher monitors the schedule, teaches lessons, facilitates, and assesses. Journals are kept; stories, articles, and poems are discussed; projects are created; and minds are challenged.

In the past, students who struggled to learn were frequently excluded from participating in activities that led to exploration, discovery, and critical thinking. With thematic instruction, however, these students can be fully included. For example, before introducing a piece of literature or informational text, it is beneficial to provide additional support for students who lack background knowledge, or who have difficulty understanding selection vocabulary and concepts. Teachers may provide this background information and preteach potentially troublesome words or concepts. Other class members who possess a good deal of background information about the 
theme may join the group and share information. This "support in advance" enables the students who struggle to fully participate in class discussions, sharing, and reading. Instead of being excluded, they are now class members who have a chance to succeed. Skills and strategies are modeled and scaffolded by the teacher and other students, and all students are provided time for group work and a chance for leadership. Thus, in thematic teaching, opportunities for success are plentiful for all learners.

There are also many opportunities for rich cross-cultural sharing. Support in advance activities, along with attention to idioms, multiple-meaning words, textual clues, realia, pictures, and various grouping configurations, assist all students in participating with the class (Ernst \& Richard, [20]). Toward the end of the theme a culminating activity draws together information that has been learned, as well as all the various materials students have read. Students' goals, projects, and learning are celebrated with parents, with other students in the school, and with each other. This final sharing enriches the learning experience for everyone and can result in a lifelong memory for the students involved.

\section{Assessment}

Both the teacher and students assess progress in a collaborative and supportive manner throughout the theme. Students' self-assessments may help determine progress in learning and may include checklists, journals, conference summaries, and written reflections. The important point is that the students themselves, regardless of age and ability, are involved in assessing what they have learned. These regular opportunities for self-reflection may be used as a final written summary to be included in a portfolio, along with other evidence of successful completion of the theme, or as part of the final project or activity.

The teacher also assesses throughout the theme, both formally and informally. Formal assessment may include specific tests of reading, writing, and the use of language. Informal assessment opportunities occur throughout, yielding authentic information about student progress. These may consist of anecdotal comments, brief conference summaries, observations of discussion groups, journals, reflections from minilessons, and learning team reports. Opportunities for evaluating participation in cooperative learning groups, following the development of social skills, and noting improvement in oral language may take place on a daily basis. Checklists may be helpful during student-teacher conferences and may assist teachers in later formulating letter grades for the theme.

It may also be helpful for parents to contribute insights into their child's learning. During parent-teacher conferencing, some of the following questions can be discussed:

- What has your child talked about at home concerning this theme?

- How much help does your child require to complete theme activities at home?

- What appears to be the aspect of this theme that is most exciting to your child?

- How does your child make use of learning about this theme?

\section{Conclusions}

Depending on a specific theme, cross-curricular reading instruction lets students contemplate problems and situations that reflect the world as they know it. For teachers and students alike, exploration and discovery become paramount; the teacher as the dispenser of knowledge is secondary. Learning is interrelated and information is connected.

When we have a look at what students think about cross-curricular reading instruction, we see the following comments: "Reading means drifting away on clouds. It means memories for a lifetime." "Reading to me means a way to relax and soothe ourselves after a hard day of school or work. Sometimes when you can't fall asleep, you can read a book. Then, if you get in trouble, you can read a book. When you get sick of TV, you can read a book."

In brief, cross-curricular reading instruction provides authentic, ongoing, multidimensional opportunities to assess students' progress, participation, and achievement. While it is important for students to enjoy thematic exploration, it is just as critical that teachers know what their students have learned.

\section{REFERENCES}

[1] Farhady, H. (2005). Techniques for Effective Reading. Tehran: Rahnama Press

[2] Hiebert, J. (1986). Conceptual and procedural knowledge: The case of mathematics. Hillsdale, NJ: Lawrence Erlbaum.

[3] Paris, S., Calfee, R., Filby, N., Hiebert, E., Pearson, P. D., Valencia, S., \& Wolf, K. (1992). "A framework for authentic literacy assessment." The Reading Teacher, 46 (2), 88-98.

[4] Anderson, R. C., Hiebert, E., Scott, J., \& Wilkinson, I. A. G. (1985). Becoming a nation of readers: The report of the Commission on Reading. Washington, D.C.: The National Institute of Education.

[5] Fielding, L., \& Pearson, P. D. (1994). "Reading comprehension: What works." Educational Leadership, 51 (5), 62-68.

[6] Reutzel, D., \& Cooter, R. (1991). "Organizing for effective instruction: The reading workshop." The Reading Teacher, 44 (8), 548-555.

[7] Hartman, D., \& Hartman, J. (1993). "Reading across texts: Expanding the role of the reader." The Reading Teacher, 47 (3), 202-211.

[8] Willis, S. (1995). "Refocusing the curriculum: Making interdisciplinary efforts work." ASCD Education Update, 37 (1), 1-8. 
[9] Ladson-Billings, B. (1992). Reading between the lines and beyond the pages: A culturally relevant approach to literacy teaching. Theory Into Practice, 31(4)

[10] Cooper, J. D. (1993). Literacy: Helping children construct meaning (2nd ed.). Boston: Houghton Mifflin Company.

[11] Fredericks, A., Meinbach, A., \& Rothlein, L. (1993). Thematic units: An integrated approach to teaching science and social studies. New York: HarperCollins.

[12] Lapp, D., \& Flood, J. (1994). "Integrating the curriculum: First steps." The Reading Teacher, 47 (5), 416-419.

[13] Walmsley, S. (1994). Children exploring their world: Theme teaching in elementary school. Portsmouth, NH: Heinemann.

[14] Willis, S. (1998). Perspectives on social Justice, disadvantage, and the mathematics curriculum. In C. Keitel (Ed.), Social justice and mathematics education

[15] Walmsley, S. (1990). Toward an integrated language arts curriculum in elementary school: Philosophy, practice, and implications.

[16] Manning, M., Manning, G., \& Long, R. (1994). Theme immersion: Inquiry-based curriculum in elementary and middle schools. Portsmouth, NH: Heinemann.

[17] Fredricks, J. A., Blumenfeld, P. C., \& Paris, A. (2004). School engagement: Potential of the concept: State of the evidence. Review of Educational Research, 74, 59-119.

[18] Vogt, M. E. (1994). "Get ready! Get set! Implementing a K-3 literature-based reading program." In B. Honig \& N. Peterson (eds.), WhatÕs a teacher to do? New curricula for new standards. Pittsburgh, PA: National Center on Education and the Economy; The New Standards Project.

[19] Slavin, R. (1990). Cooperative learning: Theory, research and practice. Englewood Cliffs, NJ: Prentice Hall.

[20] Ernst, G., \& Richard, K. (1995). "Reading and writing pathways to conversation in the ESL classroom." The Reading Teacher, 48 (4), 320-326. 